\title{
Portal dos Bebês: atualização e avaliação dos conteúdos sobre as funções orofaciais
}

\section{Website Babies Portal: updates and evaluation of the contents}

\section{regarding orofacial functions}

\author{
Ana Julia dos Passos Rizatto' (1), Camila de Castro Corrêa ${ }^{2,3}$ (D), Roberta Lopes de Castro Martinelli ${ }^{4,5}$ (D), \\ Giédre Berretin-Felix ${ }^{1}$ (D)
}

\section{RESUMO}

Objetivo: Atualizar e avaliar o conteúdo referente às funções orofaciais do Portal dos Bebês da área da Fonoaudiologia. Métodos: $\mathrm{O}$ estudo envolveu três etapas: reestruturação e atualização da seção das funções orofaciais do Portal dos Bebês, por meio de revisão bibliográfica; análise de legibilidade do novo conteúdo, por meio do Índice de Facilidade de Leitura Flesch; avaliação das seções a partir da aplicação de questionários em dois grupos de participantes: grupo A, composto por 15 fonoaudiólogos, e grupo B, composto por dez pais/cuidadores de crianças. Resultados: Foi inserida uma nova seção no website Portal dos Bebês, pertencente ao tópico Funções Orofaciais, denominada Teste da Linguinha, subdividida em cinco subseções. Além disso, o conteúdo existente foi revisado e alterações condizentes com a literatura atual foram realizadas. A avaliação da legibilidade indicou o nível instrucional mínimo exigido do ensino fundamental para a compreensão do conteúdo. O grupo A considerou o conteúdo "ótimo", além de boa avaliação para os quesitos "propriedade", "classificação do propósito", "autoria", "qualificação do autor", "atribuição", "interatividade" e "atualizações" do website. Na avaliação realizada pelo grupo $\mathrm{B}, 64 \%$ dos participantes, revelaram que o conteúdo "ajudou muito" na aquisição de conhecimentos da área, além de apresentar aumento da porcentagem de acertos após o acesso ao website. Conclusão: O conteúdo referente a Funções Orofaciais do Portal dos Bebês foi atualizado e na avaliação por ambos os grupos foi possível observar resultados positivos em relação a todos os aspectos avaliados.

Palavras-chave: Fonoaudiologia; Amamentação; Respiração; Alimentação artificial; Freio lingual; Educação a distância; Promoção da saúde

\begin{abstract}
Purpose: To update and evaluate of the contents regarding Orofacial Functions of the website Babies Portal of Speech-Language Pathology area. Methods: The study involved three steps: restructuring and updating of the orofacial functions section of the Website Babies Portal, through bibliographic review; readability analysis of the new content, through the Flesch Reading Facility Index; and the sections evaluation from the application of questionnaires in two groups: group A was composed of 15 speech therapists and group B was composed of 10 parents/caregivers of children. Results: A new section was inserted in the Portal, in orofacial functions topics, denominated "Neonatal Tongue Screening Test" subdivided into five other subsections. In addition, the existing content was reviewed and changes consistent with the current literature were performed. The readability assessment indicated the minimum instructional level required of elementary school for the understanding of content. Group A considered the content to be "excellent", as well as a good evaluation for the "property", "purpose classification", "authority", "author qualification", "attribution", "interactivity" and "updates". In the evaluation carried out by group B, $64 \%$ revealed that the content "helped a lot" in the acquisition of knowledge, in addition to increasing the percentage of hits after accessing the website. Conclusion: The content related to Orofacial Functions of the Website Babies Portal was updated and in the evaluation by both groups, it was possible to observe positive results, in relation to all aspects evaluated.
\end{abstract}

Keywords: Speech therapy; Breast-feeding; Breath; Artificial feeding; Lingual brake; Distance education; Health promotion

\footnotetext{
Trabalho realizado no Departamento de Fonoaudiologia, Faculdade de Odontologia de Bauru - FOB, Universidade de São Paulo - USP - Bauru (SP), Brasil ${ }^{1}$ Departamento de Fonoaudiologia, Faculdade de Odontologia de Bauru - FOB, Universidade de São Paulo - USP - Bauru (SP), Brasil.

${ }^{2}$ Universidade de Brasília - UnB - Brasília (DF), Brasil.

${ }^{3}$ Centro Universitário Planalto do Distrito Federal - UNIPLAN - Brasília (DF), Brasil.

${ }^{4}$ Centro de Especialização em Fonoaudiologia Clínica - CEFAC - Saúde e Educação - São Paulo (SP), Brasil.

${ }^{5}$ Hospital Santa Therezinha - Brotas (SP), Brasil.

Conflito de interesses: Não.

Contribuição dos autores: AJPR foi responsável pelo projeto, coleta, tabulação e análise dos dados e elaboração do manuscrito; CCC, RLCM e GBF supervisionaram a coleta de dados, participaram do delineamento do estudo, acompanharam a coleta e colaboraram com a análise dos dados e orientação geral das etapas de execução e elaboração do manuscrito; $\mathrm{CCC}$ realizou a submissão do manuscrito.
}

Financiamento: Nada a declarar.

Autor correspondente: Giédre Berretin-Felix. E-mail: gfelix@usp.br

Recebido: Dezembro 23, 2019; Aceito: Abril 22, 2020 


\section{INTRODUÇÃO}

O Portal dos Bebês ${ }^{(1)}$ foi desenvolvido por docentes e alunos da Faculdade de Odontologia de Bauru da Universidade de São Paulo (FOB-USP), com o objetivo fornecer informações sobre conteúdos relativos à Odontologia e à Fonoaudiologia a pais e cuidadores de bebês.

$\mathrm{Na}$ área da Fonoaudiologia, o referido website apresenta conteúdos sobre audição, motricidade orofacial e linguagem. No campo da Audiologia, são fornecidas informações a respeito do sistema auditivo, diagnóstico audiológico e reabilitação auditiva $^{(2,3)}$; quanto à Motricidade Orofacial, o website esclarece o que são as funções orofaciais, além de informar sobre hábitos orais deletérios e sobre a respiração na primeira infância ${ }^{(4)}$. $\mathrm{O}$ website aborda, ainda, aspectos relacionados à aquisição e desenvolvimento de linguagem oral ${ }^{(5)}$.

Especificamente sobre o tópico Motricidade Orofacial, os conteúdos foram elaborados e disponibilizados no formato de cinco seções, contendo informações referentes às funções orofaciais e às vantagens da amamentação natural, bem como orientações para auxiliar as mães a se prepararem para amamentar, qual o tipo de alimentação adequada para a criança até os 2 anos de idade, informações sobre os hábitos orais (chupeta, mamadeira e sucção de dedo) e como cuidar da respiração do bebê. Com o objetivo de elaborar e avaliar o conteúdo referente a Funções Orofaciais (especificamente quanto à sucção, respiração e mastigação) do Portal dos Bebês, foram aplicados questionários em dois grupos de participantes, um deles composto por pais e outro composto por profissionais fonoaudiólogos, cujos resultados obtidos para ambos os grupos indicaram boa qualidade do website ${ }^{(4)}$.

Tendo em vista a evolução constante da ciência, bem como a aprovação da Lei no 13.002 , de 20 de junho de 2014, que obriga a realização do Protocolo de Avaliação do Frênulo Lingual em todos os bebês nascidos nas maternidades do país, verificou-se a necessidade de atualizar os conteúdos teóricos no campo Motricidade Orofacial, previamente inseridos no Portal dos Bebês, além de adicionar o conteúdo sobre o Teste da Linguinha ${ }^{(6)}$.

A atualização dos conteúdos sobre as funções orofaciais, bem como sua permanente avaliação, se faz importante para manter o objetivo primário do Portal dos Bebês de informar pais e/ou cuidadores de bebês até os 3 anos de idade sobre temas importantes das áreas de Odontologia e Fonoaudiologia na primeira infância, considerando a evolução rápida e constante do conhecimento. É esperado que pais e/ou cuidadores tenham acesso fácil às informações e utilizem esse conhecimento para delinear as suas decisões.

Desta forma, o objetivo deste trabalho foi atualizar e avaliar o conteúdo referente ao tópico Funções Orofaciais do Portal dos Bebês, da área da Fonoaudiologia.

\section{MÉTODOS}

O estudo foi aprovado pelo Comitê de Ética em Pesquisa em Seres Humanos da FOB-USP, sob número 45785515.1.0000.5417. Todos os participantes foram claramente informados sobre os objetivos e procedimentos relacionados ao estudo e concordaram em participar da pesquisa, por meio da assinatura do Termo de Consentimento Livre e Esclarecido.
Para a atualização da área de Motricidade Orofacial do website, foram utilizadas as modificações propostas a partir do trabalho pioneiro da área ${ }^{(4)}$, bem como dos resultados do levantamento bibliográfico realizado, considerando vários aspectos da motricidade orofacial na infância.

Para o levantamento bibliográfico foi realizada pesquisa nas bases de dados Bireme, Lilacs e SciELO, usando os seguintes descritores que intitulam os conteúdos pertencentes à Motricidade Orofacial no Portal dos Bebês: "funções orofaciais", "amamentação natural", "respiração", "alimentação", "chupeta, mamadeira, sucção de dedo", "frênulo lingual" e "bebês". As buscas foram realizadas por dois revisores, sendo que, dos resultados gerados dos cruzamentos, foram primeiramente lidos os títulos, resumos e, por último, os artigos/teses na íntegra. Desta forma, foram incluídos conteúdos relacionados à motricidade orofacial na primeira infância, referentes à alimentação até os 24 meses, à respiração e aos hábitos de chupeta, mamadeira e sucção de dedo, selecionados após leitura e análise dos trabalhos encontrados. Como critérios de exclusão, foram desconsiderados os trabalhos que apresentaram conteúdos repetidos, abordados anteriormente no website.

A partir da literatura consultada, foram definidos os conteúdos que necessitavam de atualização, bem como os novos conteúdos que deveriam compor uma seção (aba) adicional. Além disso, foram selecionadas e produzidas imagens estáticas e dinâmicas para ilustrar a nova seção.

As novas seções foram analisadas quanto ao nível de legibilidade do conteúdo, por meio do Índice de Facilidade de Leitura Flesch (IFLF), que se baseia no comprimento das palavras e frases do texto e pode ser interpretado utilizando uma escala de sete níveis de facilidade: muito difícil (0-30 pontos), difícil (40-50), razoavelmente difícil (50-60), padrão (60-70), razoavelmente fácil (70-80), fácil (80-90) e muito fácil (90-100) ${ }^{(7)}$.

Para a avaliação do tema Motricidade Orofacial do website, foram constituídos dois grupos: grupo A, composto por 15 fonoaudiólogos, atuantes em Motricidade Orofacial, e grupo B, composto por dez pais e/ou cuidadores de bebês de 0 (zero) até 36 meses de idade. Inicialmente, ambos os grupos realizaram um cadastro, envolvendo informações pessoais (idade, sexo, unidade de federação), bem como informações sobre acesso à internet (tipo de conexão utilizada, local de acesso). Para o grupo A, foram solicitados os dados de titulação, tempo de atuação profissional e local de atuação (rede privada ou pública). Para o grupo $\mathrm{B}$, foram coletadas informações a respeito da escolaridade, renda familiar, estado civil, idade da criança, relação com a criança (pai, mãe ou cuidador).

O grupo A respondeu ao questionário Health on the Net Code (HONcode) modificado ${ }^{(8)}$, que avalia a qualidade técnica da informação fornecida pelo website, baseado na propriedade, propósito, autoria, interatividade e atualizações, pontuando cada item em 0, 1 ou 2. Quanto maior a pontuação obtida (em um total de 13 pontos), melhor é a qualidade do website. Esse grupo também respondeu a questões para cada subseção da área da Motricidade Orofacial, considerando a abrangência do conteúdo técnico em péssima (1 ponto), ruim (2), regular (3), boa (4), ou ótima (5 pontos) $)^{(4)}$. Quanto maior a pontuação obtida, melhor a abrangência de cada assunto abordado pela área da Motricidade Orofacial do website.

O grupo B respondeu a um questionário após acessar as seções, para avaliar a contribuição para aquisição de conceitos, com questões para cada subseção do campo Motricidade Orofacial, informando se o conteúdo "não ajudou", "ajudou pouco", 
"ajudou mais ou menos", “ajudou”, ou "ajudou muito" para adquirir novos conhecimentos. A última questão deste mesmo questionário foi a respeito de quão satisfeito o participante estava com as informações fornecidas no Portal dos Bebês, de modo geral, podendo responder: "nem um pouco", "um pouco", "mais ou menos", "satisfeito", ou "muito satisfeito". O segundo questionário, elaborado pelos autores do estudo, foi respondido por esse grupo antes e depois do acesso ao website, para avaliar o nível de conhecimento sobre alimentação infantil, respiração, hábitos orais e o Teste da Linguinha (Apêndice 1).

Os participantes tiveram, primeiramente, acesso ao conteúdo do Portal dos Bebês para, em seguida, completar as informações dos questionários que avaliam a qualidade do website e a qualidade do conteúdo técnico fornecido, dentro de um prazo de 20 dias, a partir da data do primeiro acesso, até o envio dos questionários devidamente preenchidos.

\section{RESULTADOS}

Os resultados são apresentados em três partes: atualização do conteúdo, análise da legibilidade e avaliação do conteúdo.

\section{Atualização do conteúdo da área de Motricidade Orofacial do website}

\section{Seleção do conteúdo}

A busca realizada a partir dos descritores determinados possibilitou encontrar 15 artigos, que foram analisados e tiveram seus achados comparados à versão inicial ${ }^{(4)}$. Assim, foi verificada adequação dos conteúdos relacionados aos tópicos: "Alimentação até os 6 meses"((,10) "Alimentação dos 6 aos 24 meses"(11-13) e "Respiração"(14). Além disso, foi necessário inserir e/ou modificar os seguintes conteúdos no website:

- Tópico "Chupeta, mamadeira e sucção de dedo": aborda os diferentes tipos de bicos para mamadeira e chupeta, sendo que havia indicação do bico ortodôntico, apontando-o como a melhor opção para favorecer o padrão de sucção mais adequado. Tendo em vista que não foi encontrada evidência científica que o bico ortodôntico causaria menores danos, quando comparado ao bico convencional ${ }^{(15)}$, optou-se por adequar as orientações, informando que o bico ortodôntico é citado na literatura, porém não é indicado como melhor opção. Também foi inserida a informação sobre a necessidade do tamanho adequado do bico, considerando o tamanho da cavidade oral do bebê, devendo ser trocado mediante o crescimento da boca do bebê, conforme aponta a literatura atual ${ }^{(16-19)}$, a fim de direcionar os pais e/ou cuidadores na escolha do bico;

- Foi inserido um novo tópico, contendo informações sobre o "Teste da Linguinha", tendo em vista que no ano de 2014, foi aprovada a lei que obriga a realização do Protocolo de Avaliação do Frênulo Lingual em todos os bebês nascidos nas maternidades do Brasil. As informações referentes a esse teste foram inseridas no website, com linguagem simples e ilustrações explicativas, para que os pais e/ou cuidadores pudessem compreender. Estas informações foram setorizadas em um novo tópico, denominado "Teste da Linguinha", subdividido em cinco seções. A escolha dos subtópicos foi realizada com base na Cartilha do Teste da Linguinha ${ }^{(6,20-24)}$.

\section{Seleção das imagens}

O website Portal dos Bebês apresenta layout padronizado das ilustrações, desenvolvidas por uma funcionária designer gráfica do Setor de Tecnologia Educacional da instituição envolvida. Assim, as figuras introduzidas nesta atualização foram desenvolvidas pela referida profissional, com exceção de uma imagem que já havia sido disponibilizada na campanha que promoveu o Teste da Linguinha e pode ser encontrada na internet ${ }^{(25)}$.

Esta atualização contou com a inserção de cinco novas imagens estáticas, sendo uma delas a imagem que se tornou conhecida símbolo do Teste da Linguinha. Duas imagens foram inseridas com o intuito de exemplificar a maneira considerada adequada para a mãe posicionar o bebê para a realização da avaliação do frênulo lingual e para a amamentação. As outras duas imagens exemplificam um frênulo de língua normal e um alterado. Também foram inseridos dois vídeos, um deles com o objetivo de demonstrar como a avaliação é realizada e o segundo vídeo abordando a importância do teste, ambos produzidos por uma das autoras do Teste da Linguinha, com acesso livre na internet ${ }^{(1)}$.

\section{Elaboração do texto}

A seguir, são apresentadas as informações contidas em cada uma das cinco novas subseções inseridas no Portal dos Bebês:

- O que é língua presa? - Língua presa é uma alteração comum, mas, muitas vezes, ignorada. Ela está presente desde o nascimento e ocorre quando uma pequena porção de tecido, que deveria ter desaparecido durante o desenvolvimento do bebê na gravidez, permanece na parte de baixo da língua, limitando seus movimentos;

- O que é o Teste da Linguinha? - O Teste da Linguinha é um exame padronizado que possibilita diagnosticar e indicar o tratamento precoce das limitações dos movimentos da língua, causadas pela língua presa, que podem comprometer as funções exercidas pela língua: sugar, engolir, mastigar e falar. O Protocolo de Avaliação do Frênulo da Língua em Bebês (Teste da Linguinha) foi desenvolvido durante o mestrado da fonoaudióloga Roberta Lopes de Castro Martinelli, na FOB-USP. É lei: O Projeto de Lei ${ }^{\circ} 4.832 / 12$, de autoria do Deputado Federal Onofre Santo Agostini, "obriga a realização do Protocolo de Avaliação do Frênulo da Língua em Bebês, em todos os hospitais e maternidades do Brasil", foi sancionado pela Presidência da República e se converteu na Lei $n^{\circ} 13.002$, de 20 de junho de 2014;

- Como é realizado o teste - O Teste da Linguinha deve ser realizado por um profissional da área da saúde qualificado, como, por exemplo, o fonoaudiólogo. Eledeve elevar a língua do bebê, para verificar se a língua está presa, e também observar o bebê chorando e sugando. 
O exame não tem contraindicações. Recomenda-se que a avaliação do frênulo da língua seja, inicialmente, realizada na maternidade. A avaliação precoce é ideal para que os bebês sejam diagnosticados e tratados com sucesso. O que fazer se a maternidade ou hospital não tiver realizado o teste? Avise o pediatra ou profissional da saúde logo, na primeira consulta. Ele deverá encaminhar o bebê para os locais que estejam preparados para realizar o teste. Orientações gerais para realização do teste: 1. Posicionamento do bebê: a mãe ou responsável deve apoiar a nuca do bebê no espaço entre o braço e o antebraço. Em seguida, deve segurar as mãos do bebê. 2. Elevação da língua do bebê: é utilizada uma manobra específica, por meio da qual o profissional introduz os dedos indicadores enluvados embaixo da língua, para que se possa fazer sua elevação;

- Importância do teste - Quando um bebê nasce com a língua presa, normalmente parentes próximos podem apresentar o mesmo problema. Por falta de informação, muitos sofrem em silêncio as várias dificuldades que essa alteração pode causar. Há bebês com dificuldades para mamar, causando estresse, tanto para ele, quanto para a mãe; crianças, jovens e adultos com dificuldades na mastigação/deglutição e alterações na fala, afetando a comunicação, o relacionamento social e o desenvolvimento profissional. Além disso, diferentes movimentos da língua, como, por exemplo, lamber sorvete e beijar podem ser difíceis de realizar. É importante que seu bebê faça o exame o mais cedo possível, preferencialmente no primeiro mês de vida, para que se descubra, com a maior antecedência, se tem língua presa, evitando dificuldades na amamentação, possível perda de peso e, principalmente, o desmame precoce, com introdução desnecessária da mamadeira. Seguir essas recomendações faz toda diferença para a amamentação e, consequentemente, para a boa saúde do seu filho;

- Quando é necessário realizar o reteste e como é feito - Nos casos onde houver dúvida, ou não for possível visualizar o frênulo lingual, o bebê é encaminhado para reteste com 30 dias de vida. O profissional deve orientar os pais sobre possíveis dificuldades na amamentação, para que não ocorra o desmame precoce nesse período. Para o reteste é necessário: 1. Condição do bebê: é necessário que o bebê esteja bem acordado e com fome (próximo à hora da mamada); 2. Posicionamento do bebê: a mãe ou responsável deve apoiar a nuca do bebê no espaço entre o braço e o antebraço. Em seguida, deve segurar as mãos do bebê; 3 . Elevação da língua do bebê: é utilizada uma manobra específica: o profissional introduz os dedos indicadores enluvados embaixo da língua, para que se possa fazer a elevação da língua e visualizar o frênulo; 4. Avaliação durante a sucção na amamentação: o bebê deverá ser amamentado enquanto o profissional realiza a avaliação da sucção, deglutição e respiração do bebê.

A seguir, são apresentadas algumas imagens demonstrativas das subseções referentes ao Teste da Linguinha, disponibilizadas no Portal dos Bebês (Figura 1).

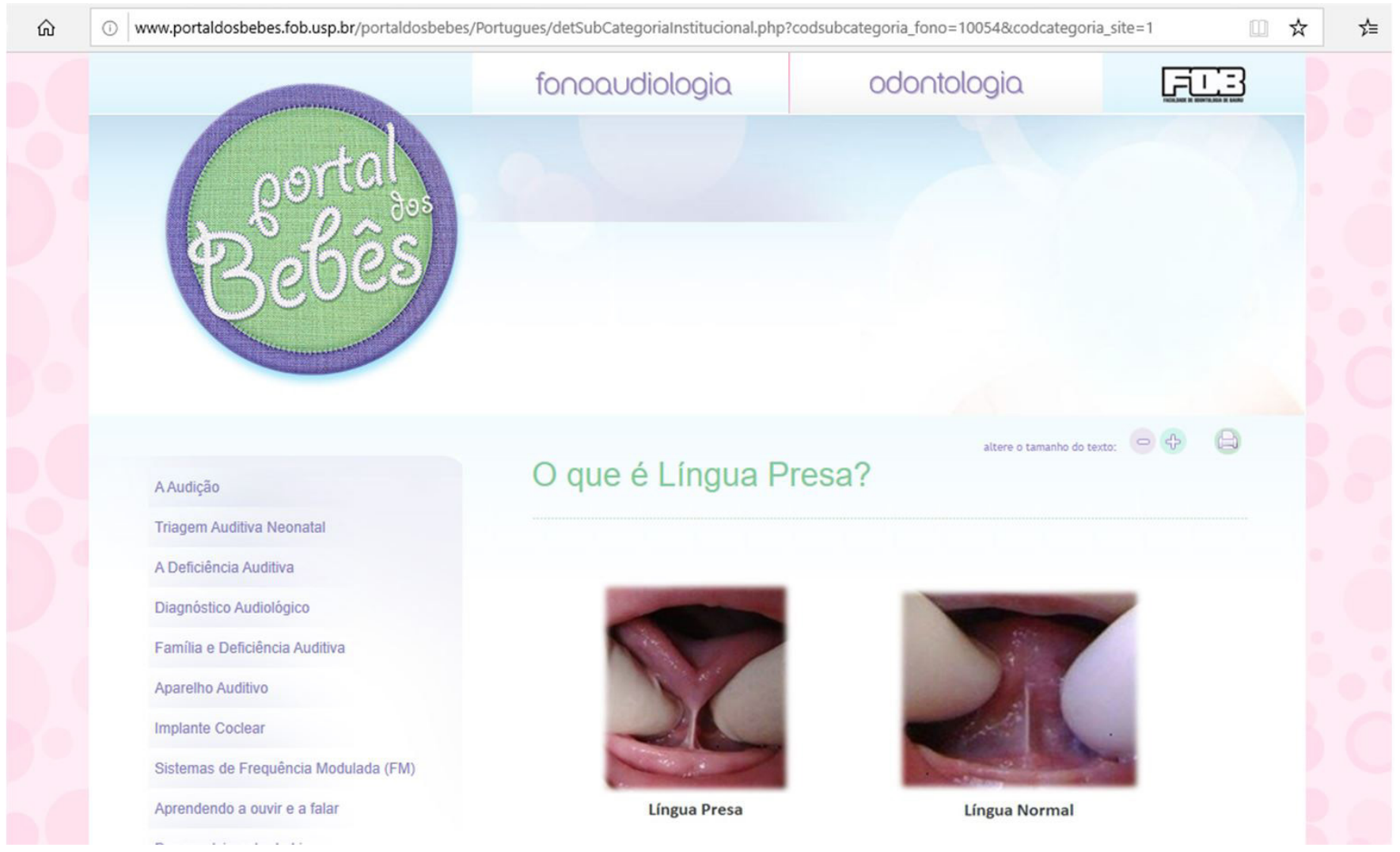

Figura 1. Exemplo de ilustração das novas subseções referentes ao Teste da Linguinha, criadas mediante a atualização do website 


\section{Análise da legibilidade}

A análise da legibilidade foi realizada por meio da aplicação do Índice de Facilidade de Leitura Flesch. Este instrumento foi aplicado em cada uma das subseções do Teste da Linguinha, individualmente, e em todas elas em conjunto (Tabela 1).

\section{Avaliação da área de Motricidade Orofacial do website}

\section{Grupo A - Fonoaudiólogos}

Este grupo foi composto por 15 fonoaudiólogos, oriundos de 6 cidades diferentes dos estados de São Paulo e Ceará, todos atuantes na rede pública de saúde, com tempo mínimo de atuação profissional de 1 ano e 6 meses e o tempo máximo de 23 anos de experiência profissional (mediana de 5 anos de atuação). Todos os participantes informaram ter acesso à internet com conexão do tipo banda larga, $W i-F i$ e via rádio.

Em relação ao questionário HONcode modificado, observou-se que, para a maior parte dos participantes, a "propriedade/patrocínio" foi claramente declarada; houve distinção da finalidade das informações fornecidas; a autoria foi nitidamente determinada, sendo o autor o profissional da saúde; a atribuição para todas as declarações que contêm informações de fatos está presente; houve claro convite para comentários ou perguntas, por meio de um endereço de e-mail ou link para um formulário e a data da primeira postagem foi fornecida, mas não há informação sobre a data da última revisão ou frequência de atualizações (Figura 2).

Os resultados referentes ao outro questionário respondido pelo grupo de profissionais, a respeito da abrangência dos conteúdos da área de Motricidade Orofacial do website, estão expostos na Figura 3.

\section{Grupo B - Pais/Cuidadores}

O grupo $\mathrm{B}$ foi composto por 5 mães e 5 cuidadores de bebês, na faixa etária de 26 a 58 anos, responsáveis por bebês com idades entre 3 e 35 meses. Os participantes desse grupo eram oriundos de 7 cidades diferentes dos estados de São Paulo, Rio de Janeiro e Paraná. Deste grupo, 3 integrantes possuíam ensino superior completo, outros 3 possuíam ensino superior incompleto, 2 deles possuíam ensino médio completo e os outros 2, ensino fundamental completo. A renda familiar mínima declarada foi de 1 a 3 salários mínimos e a máxima, mais de 7 salários mínimos. Todos os participantes relataram ter acesso à internet, com a conexão do tipo banda larga e Wi-Fi.

Os resultados obtidos no questionário sobre a importância dos conteúdos para adquirir novos conhecimentos estão dispostos na Figura 4.

A Figura 5 apresenta os resultados referentes ao questionário respondido antes e depois do acesso ao website, para a mensuração do nível de conhecimento.

Tabela 1. Resultado da análise da legibilidade por meio da utilização do Índice de Facilidade de Leitura Flesch para cada uma das subseções da seção do Teste da Linguinha no Portal dos Bebês

\begin{tabular}{lcc}
\hline \multicolumn{1}{c}{ Subseção } & IFLF & Classificação \\
\hline O que é língua presa? & $55 \%$ & Razoavelmente difícil \\
O que é o Teste da Linguinha? & $43 \%$ & Difícil \\
Como é realizado o teste & $72 \%$ & Razoavelmente fácil \\
Importância do teste & $34 \%$ & Difícil \\
Quando é necessário realizar o reteste e como é feito & $56 \%$ & Razoavelmente difícil \\
Todo conteúdo & $56 \%$ & Razoavelmente difícil \\
\hline
\end{tabular}

Legenda: IFLF = Índice de Facilidade de Leitura Flesch

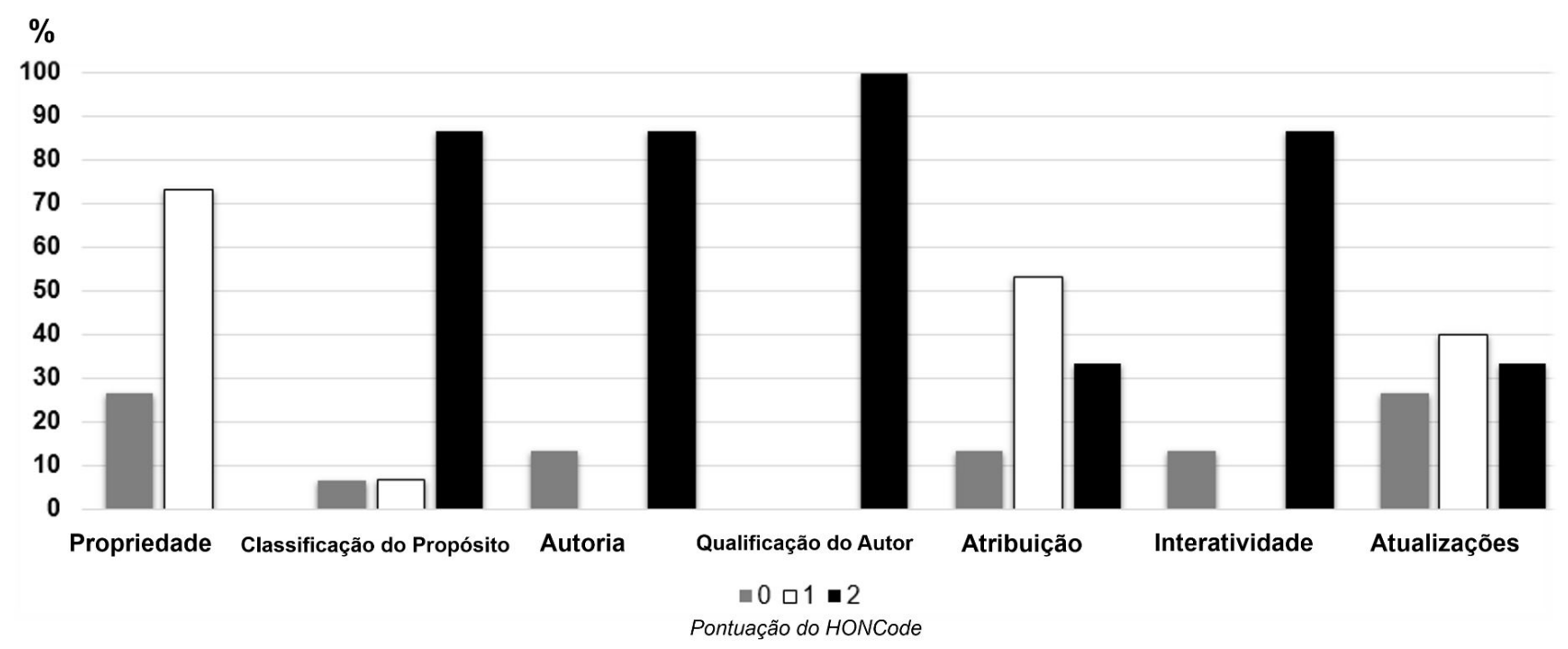

Figura 2. Resultados do questionário HONcode (Health on the Net Code) modificado, em relação aos sete aspectos analisados: propriedade, classificação do propósito, autoria, qualificação do autor, atribuição, interatividade e atualizações 


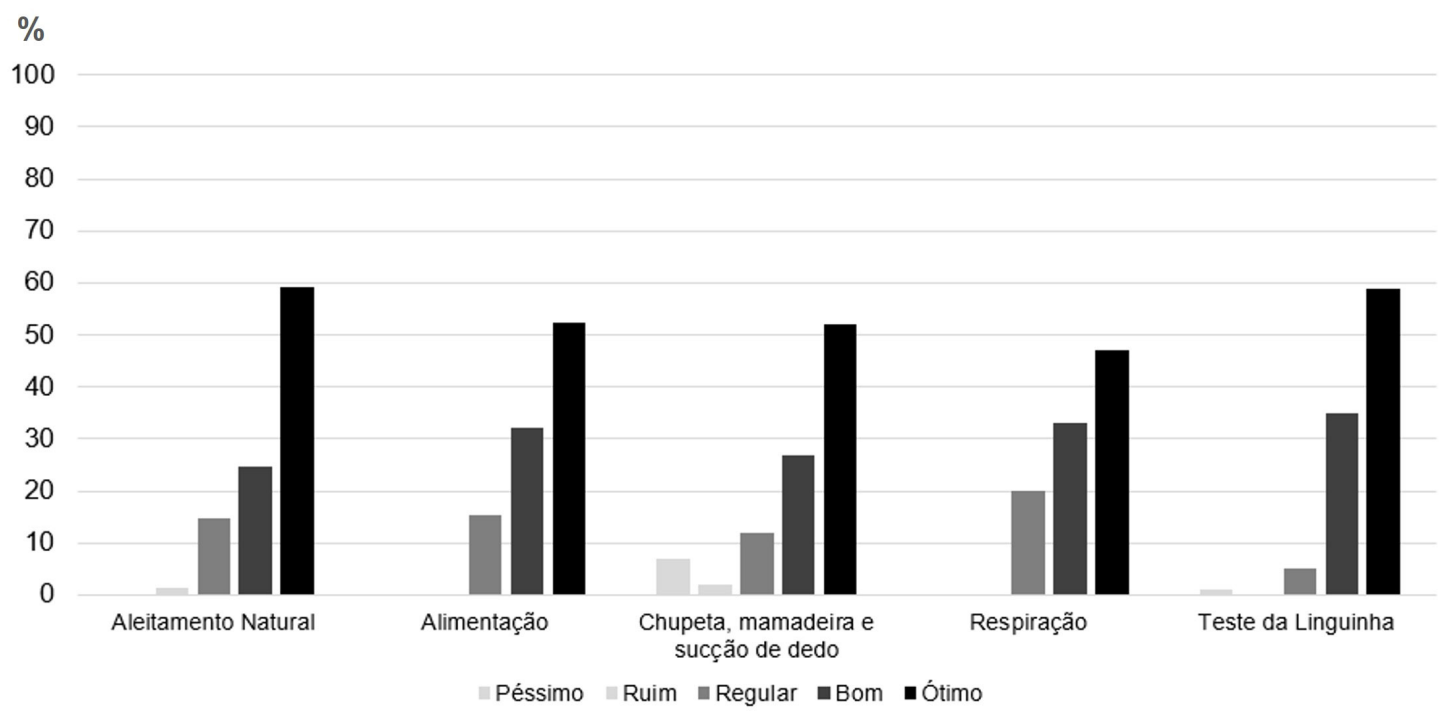

Figura 3. Resultados obtidos sobre a abrangência das informações, a partir da análise do Grupo A

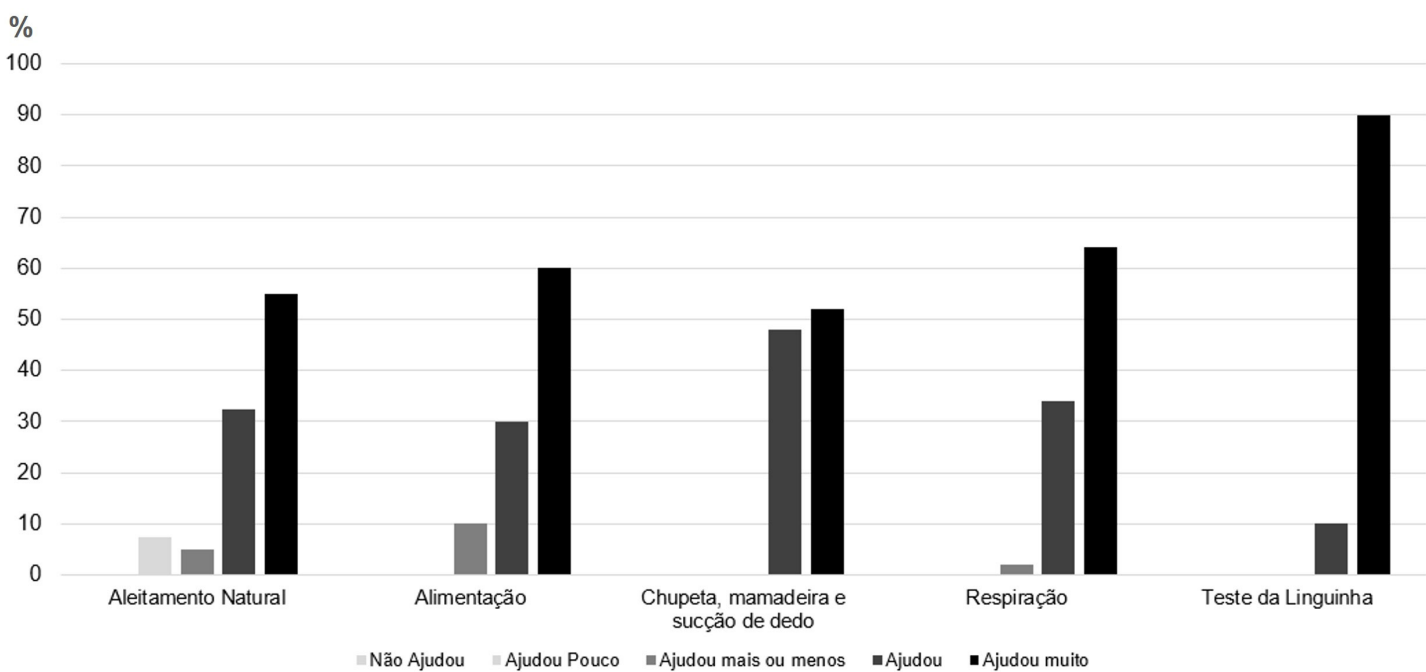

Figura 4. Resultados obtidos da contribuição para conceitos adquiridos, segundo o Grupo B

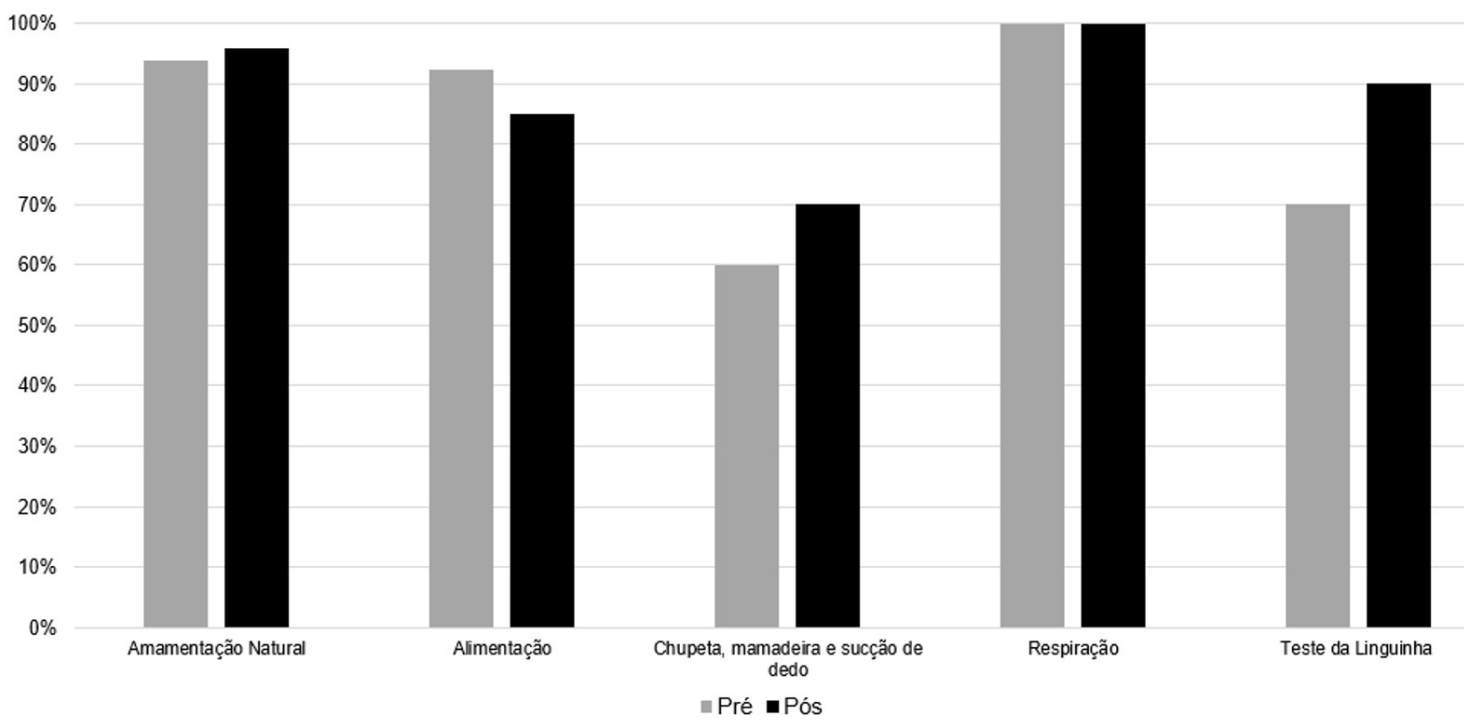

Figura 5. Resultados da avaliação do nível do conhecimento antes e depois do acesso ao website Portal dos Bebês, pelo Grupo B 


\section{DISCUSSÃO}

A atualização das seções sobre as Funções Orofaciais do website Portal dos Bebês se fez necessária, considerando as novas descobertas científicas da área, a fim de manter o cumprimento do principal objetivo da elaboração do website, fornecer informações atuais, de qualidade e de fácil entendimento para pais e/ou cuidadores de bebês.

Cada uma das seções teve seus conteúdos comparados com a literatura e atualizados, quando necessário. Esta preocupação se justifica pela dinamicidade e constante evolução dos conceitos na área da saúde, tornando necessária a atualização constante. Estudos sobre o tema são escassos, podendo ser citado o trabalho na área da saúde, que identificou que $67,7 \%$ dos sites sobre anomalia vascular foram atualizados no último ano ${ }^{(26)}$. Especificamente sobre as funções orofaciais, observou-se que apenas metade dos sites cumpre os princípios do Health On The Net Code (HONcode), sendo que, dentre estes princípios, está a atualização ${ }^{(27)}$.

Na seção "Alimentação até os 6 meses", as informações sobre aleitamento materno, sucção nutritiva e não nutritiva foram consideradas adequadas ao conhecimento atual ${ }^{(9,10)}$, bem como as dos tópicos “Alimentação dos 6 aos 24 meses"(11-13) e "Respiração"(14). Já no tópico "Chupeta, mamadeira e sucção de dedo", houve a necessidade de atualizar o conteúdo, mediante literatura recente, trazer uma revisão sistemática com metanálise, demonstrando não existir diferenças entre as alterações no sistema estomatognático decorrentes da utilização do bico convencional e do bico ortodôntico ${ }^{(15)}$.

$\mathrm{Na}$ fase de atualização, verificou-se a necessidade da modificação dos conteúdos inseridos no website anteriormente ${ }^{(4)}$, bem como a inserção do conteúdo referente à avaliação do frênulo lingual em bebês, popularmente conhecido como Teste da Linguinha ${ }^{(6)}$, sendo a sua realização obrigatória em todos os bebês nascidos nas maternidades do Brasil, mas ainda pouco conhecido quanto aos seus objetivos e sua importância, pela população. Vale destacar que, com a sanção dessa lei, a avaliação do frênulo lingual ganhou maior notoriedade entre os profissionais da área da saúde, entre as famílias de bebês e a população em geral, levando o Protocolo de Avaliação do Frênulo da Língua em Bebês a ganhar espaço na mídia e, naturalmente, aumentar o número de dúvidas a respeito desse assunto. Tanto o protocolo, quanto a sua triagem neonatal do frênulo lingual foram validados para a população brasileira ${ }^{(20,21)}$.

Quanto ao conteúdo que já integrava o Portal dos Bebês, houve a adequação do texto, para que ficasse claro que, embora exista a orientação para uso de bicos ortodônticos, não há, na literatura, comprovação sobre sua eficácia em prevenir alterações dento-oclusais, ou de sua superioridade aos demais bicos ${ }^{(15)}$.

O Índice de Facilidade de Leitura Flesch, aplicado em todas as subseções referentes ao Teste da Linguinha, foi considerado razoavelmente difícil. Nas seções avaliadas isoladamente, foram encontrados os seguintes resultados: "O que é língua presa" e "Quando é necessário realizar o reteste e como é feito" = razoavelmente difícil; "O que é o Teste da Linguinha" e "Importância do teste" = difícil; "Como é realizado o teste" = razoavelmente fácil. Desta forma, buscando facilitar o entendimento, foram utilizadas cinco imagens estáticas e dois vídeos, tendo em vista que os recursos audiovisuais possibilitam ampliar os esclarecimentos dos assuntos abordados ${ }^{(28,29)}$. Outros websites sobre as funções orofaciais apresentaram o Índice de
Facilidade de Leitura Flesch, em média, na classificação padrão, exigindo o mesmo nível instrucional do "razoavelmente difícil", que é o ensino fundamental ${ }^{(27)}$.

O presente estudo também realizou avaliações por meio de diferentes instrumentos, para averiguar a qualidade e a influência sobre o conhecimento de pais e/ou cuidadores de bebês, bem como de profissionais atuantes na área, a respeito da motricidade orofacial na primeira infância.

O grupo composto por fonoaudiólogos avaliou a qualidade técnica do website, sendo positivamente avaliada nos itens de propriedade/patrocínio, autoria, atribuição e interatividade. Aproximadamente, $83 \%$ dos profissionais julgaram ótima/boa a abrangência dos conteúdos avaliados, indicando confiabilidade das informações de saúde disponibilizadas na internet ${ }^{(30)}$. Estes achados são similares ao estudo realizado para elaboração das seções sobre as funções orofaciais do website Portal dos Bebês ${ }^{(4)}$.

$\mathrm{Na}$ avaliação realizada pelo grupo de pais/cuidadores de bebês, observou-se que, para mais de $94 \%$, o conteúdo "ajudou" ou "ajudou muito" na compreensão do assunto, considerando todas as seções. Tais achados superaram os resultados do primeiro estudo, que apresentou uma taxa de $88 \%{ }^{(4)}$. Esse grupo ainda revelou aumento da porcentagem de acertos das perguntas sobre o conteúdo, após o acesso ao website, em três seções. Não há estudos publicados que possibilitem tal comparação.

Com a realização deste trabalho, foi possível disponibilizar e avaliar o conteúdo atual referente à área de Motricidade Orofacial da Fonoaudiologia, no que diz respeito à primeira infância, no website Portal dos Bebês. Entretanto, ressalta-se a importância de se investir em ações de promoção da saúde que também alcancem a população que ainda não tem acesso à internet, sendo esta proposta dependente de tal tecnologia. Devem ser consideradas as diversidades do Brasil, um país com características e possibilidades heterogêneas, buscando superar tal limitação no alcance deste conteúdo para mais pessoas.

O Portal dos Bebês conta com a participação de 24 professores e alunos da FOB-USP, fornece informações sobre Fonoaudiologia e Odontologia e pode ser considerado um importante instrumento de orientação aos pais e cuidadores de bebês, porém, atualmente, ainda é pouco utilizado para este objetivo. Maior divulgação para melhor utilização deste instrumento é necessária.

Ambos os grupos de avaliadores, foram convidados a compartilhar sugestões para o website. O grupo composto por profissionais fonoaudiólogos, contribuiu, principalmente, com sugestões relevantes para melhora da qualidade do conteúdo oferecido, porém, não houve tempo hábil para fazer alterações no website depois do término das avaliações. Portanto, a realização de um novo trabalho que possa realizá-las seria interessante. Além disso, é muito importante que as informações disponíveis sejam atualizadas com determinada frequência para que se mantenham sempre acompanhando as descobertas científicas da área.

\section{CONCLUSÃO}

O conteúdo referente a Funções Orofaciais do Portal dos Bebês foi atualizado por meio da adequação da subseção denominada "Chupeta", com a inserção de uma nova seção, denominada "Teste da Linguinha"(1). O website, na área da Motricidade Orofacial foi avaliado por fonoaudiólogos e pais/cuidadores de bebês, indicando boa qualidade técnica do conteúdo e boa possibilidade de auxílio para adquirir novos conhecimentos sobre 
as funções orofaciais, além de adequado nível de legibilidade, compatível com o nível instrucional mínimo exigido do ensino fundamental para a compreensão do conteúdo.

\section{AGRADECIMENTOS}

Programa de Educação Tutorial em Fonoaudiologia (bolsa MEC/SeSu).

\section{REFERÊNCIAS}

1. USP: Universidade de São Paulo [Internet]. 2019 [citado em 2019 Dez 23]. Disponível em: http://portaldosbebes.fob.usp.br/

2. Bastos BG, Ferrari DV. Portal dos Bebês - Seção aparelho auditivo: avaliação por pais de crianças deficientes auditivas. Rev CEFAC. 2014;16(1):72-82. http://dx.doi.org/10.1590/1982-0216201413412.

3. Bastos BG, Ferrari DV. Babies' Portal website hearing aid section: assessment by audiologists. Int Arch Otorhinolaryngol. 2014;18(4):33846. PMid:25992119.

4. Correa CC, Pauleto ARC, Ferrari DV, Berretin-Felix G. Website Babies Portal: development and evaluation of the contents regarding orofacial functions. J Appl Oral Sci. 2013;21(6):581-9. http://dx.doi. org/10.1590/1679-775720130267.

5. Martins A, Franco EC, Caldana ML. Elaboração e Avaliação de um website sobre o desenvolvimento da linguagem infantil: portal dos Bebês - desenvolvimento da linguagem. Rev CEFAC. 2015;17(1):15968. http://dx.doi.org/10.1590/1982-021620152614.

6. Martinelli RLC, Marchesan IQ, Berretin-Felix G. Lingual frenulum evaluation protocol for infants: relationship between anatomic and functional aspects. Rev CEFAC. 2013;15(3):599-610. http://dx.doi. org/10.1590/S1516-18462013005000032.

7. Biondo-Simões MLP, Martynetz J, Ueda FMK, Olandoski M. Compreensão do termo de consentimento. Rev Col Bras Cir. 2007;34(3):183-8. http://dx.doi.org/10.1590/S0100-69912007000300009.

8. Barbosa AL, Martins EN. Avaliação da informação dos pacientes sobre miopsias e fotopsias através da Internet. Arq Bras Oftalmol. 2007 Set-Out;70(5):839-43. PMid:18157311.

9. Fernandes ATS, Ladewig VM, Almeida-Pedrin RR, Conti ACCF, Marta SN. The relationship between breastfeeding and malocclusion. Ortodontia. 2016;49(2):157-62.

10. Knoll LR. Influence of breastfeeding on craniofacial growth and development under the concept of neuro oclusion rehabilitation. Ortodontia. 2015;48(2):137-42.

11. Santos SP, Vieira GO, Scavuzzi AIF, Gomes IS Fo. Feeding practices and dental caries: approach on early childhood. Rev Assoc Paul Cir Dent. 2016;70(1):12-8.

12. Silva D, Nóbrega L, Valente A, Dias C, Almeida F, Cruz JL, et al. Maternal breastfeeding and the characterization of feeding habits in early infancy: the experience of São Tomé e Príncipe. Rev Bras Saúde Mater Infant. 2014;14(3):269-77. http://dx.doi.org/10.1590/ S1519-38292014000300008.

13. Vendruscolo JF, Bolzan GM, Crestani AH, Souza APR, Moraes AB. The relation between breast-feeding, transition and child development risk. Distúrb Comun. 2012;24(1):41-52.
14. Yamaguchi H, Tada S, Nakanishi Y, Kawaminami S, Shin T, Tabata $\mathrm{R}$, et al. Association between mouth breathing and atopic dermatitis in Japanese children 2-6 years old: a population-based cross-sectional study. PLoS One. 2015;10(4):e0125916. http://dx.doi.org/10.1371/ journal.pone.0125916. PMid:25915864.

15. Corrêa CC, Bueno MRS, Lauris JRP, Berretin-Felix G. Interference of conventional and orthodontic nipples in system stomatognatic: systematic review. CoDAS. 2016;28(2):182-9. PMid:27191883.

16. Adair SM, Milano M, Dushku JC. Evaluation of the effects of orthodontic pacifiers on the primary dentitions of 24- to 59-month-old children: preliminary study. Pediatr Dent. 1992;14(1):13-8. PMid:1502109.

17. Zardetto CG, Rodrigues CR, Stefani FM. Effects of different pacifiers on the primary dentition and oral myofunctional strutures of preschool children. Pediatr Dent. 2002;24(6):552-60. PMid:12528948.

18. Mesomo C, Losso EM. Avaliação dos efeitos do uso prolongado de chupetas convencionais e ortodônticas sobre a dentição decídua. JBP: Rev Ibero Am Odontopediatr Odontol Bebê. 2004;7(38):360-4.

19. Meyers AMPH, Hertzberg JDMD. Bottle-feeding and malocclusion: is there an association? Am J Orthod Dentofacial Orthop. 1988;93(2):14952. http://dx.doi.org/10.1016/0889-5406(88)90293-4. PMid:3422530.

20. Martinelli RLC, Marchesan IQ, Berretin-Felix G. Lingual frenulum protocol with scores for infants. Int J Orofacial Myology. 2012;38:10412. PMid:23362754.

21. Martinelli RLC, Marchesan IQ, Rodrigues AC, Berretin-Felix G. Tongue frenulum evaluation protocol in babies. Rev CEFAC. 2012;14(1):13845. http://dx.doi.org/10.1590/S1516-18462012000100016.

22. Martinelli RLC, Marchesan IQ, Berretin-Felix G. Longitudinal study of the anatomical characteristics of the lingual frenulum and comparison to literature. Rev CEFAC. 2014;16(4):1202-7. http:// dx.doi.org/10.1590/1982-021620149913.

23. Martinelli RLC, Marchesan IQ, Gusmão RJ, Honório HM, BerretinFelix G. The effects of frenotomy on breastfeeding. J Appl Oral Sci. 2015;23(2):153-7. http://dx.doi.org/10.1590/1678-775720140339. PMid:26018306.

24. SBFA: Sociedade Brasileira de Fonoaudiologia. Teste da linguinha [Internet]. São Paulo: SBFA; 2014 [citado em 2019 Dez 23]. Disponível em: http://www.sbfa.org.br/portal/pdf/testelinguinha_2014_livro.pdf

25. EBC: Empresa Brasil de Comunicação. Fonoaudióloga defende obrigatoriedade do teste da linguinha [Internet]. 2014 [citado em 2019 Dez 23]. Disponível em: http://www.ebc.com.br/infantil/parapais/2014/01/fonoaudiologa-defende-obrigatoriedade-do-teste-dalinguinha

26. Davis KS, McCormick AA, Jabbour N. What might parents read: sorting webs of online information on vascular anomalies. Int J Pediatr Otorhinolaryngol. 2017 Fev;93:63-7. http://dx.doi.org/10.1016/j. ijporl.2016.12.004. PMid:28109499.

27. Correa CC, Ferrari DV, Berretin-Felix G. Quality, range and legibility in websites related to orofacial functions. Arq Int Otorrinolaringol. 2013;17(4):358-62.

28. Cruvinel OV. Novas tecnologias e o currículo escolar. Cad FUCAMP. 2006;5(5):1-11.

29. Veiga EC. A psicopedagogia modular: uma nova perspectiva no campo da avaliação. Psicol. Argum. 2010;28(60):11-5.

30. Pacios M, Campos CJR, Martha AS, Barra PSC. Os sites de medicina e saúde frente aos princípios éticos da Health on the Net Foundation - HON. Rev Bioet. 2010;18(2):483-96. 
Apêndice 1. Formulário para os pais (preenchido antes e após acesso ao website)

Questionário sobre conhecimento de Alimentação Infantil, Respiração e Hábitos Orais

Este questionário faz parte de uma pesquisa que tem como objetivo melhorar o fornecimento de informações à comunidade a respeito da Alimentação Infantil, Respiração, Hábitos Orais e o Teste da Linguinha. Esperamos que você possa nos ajudar a identificar quais informações são importantes de serem fornecidas.

Pedimos, por favor, para que você preencha o questionário abaixo. Você ou suas respostas não serão identificadas. A sua opinião é muito importante para nós. Agradecemos a sua atenção e o tempo que levou para responder a este questionário.

1- Você acha que amamentar no peito é importante para um bom desenvolvimento dos dentes e da face de seu bebê?

( ) SIM ( ) NÃO ( ) um pouco

2- Até que idade é necessário amamentar?

( ) 3 meses

( ) 6 meses

( ) 1 ano

( ) 3 anos

( ) Outra

3- É mais barato e adequado alimentar o bebê até os seis meses por meio de:

( ) Leite tipo $\mathrm{C}$ de saquinho

( ) Papinhas de frutas, verduras e legumes.

( ) Leite de caixinha

( ) Leite materno

( ) Chás

4- Em que idade a papinha deve ser introduzida na alimentação do bebê que está sendo amamentado com o leite materno?

( ) 3 meses

( ) 6 meses

( ) 1 ano

( ) 3 anos

( ) Outra

5- O preparo da mãe para o aleitamento materno inicia-se:

( ) Desde o período pré-natal

( ) Após o nascimento do bebê

( ) A partir do momento em que o bebê encontre dificuldades para sugar o leite materno.

6- Assinale apenas uma alternativa que você considera correta:

( ) O bebe deve permanecer dormindo durante o aleitamento materno

( ) A mãe deve fornecer apenas a mama que o bebe tiver maior facilidade para sugar o leite.

( ) O bebe deve permanecer posicionado mais sentado possível.

7- Quando você acha que deve ser iniciada a limpeza da boca do bebê?

( ) Quando aparecerem os primeiros dentes da frente

( ) Só quando nascem os dentes do fundo

8- Limpar o nariz do bebê previne doenças respiratórias?

( ) SIM ( ) NÃO ( ) um pouco

9- O nariz do bebê deve ser lavado com soro fisiológico?

( ) Uma vez ao dia

( ) Uma vez por semana

( ) Não é necessário lavar o nariz do bebê

10- Com qual idade o bebê já deverá consumir alimentos com a consistência normal, semelhante a que o adulto ingere?

( ) 6 meses

( ) 12 meses

( ) 18 meses

( ) 24 meses

( ) 30 meses

11- A alimentação complementar ao leite materno deve ser oferecida em horários fixos.

( ) $\operatorname{SIM}($ ) NẪO

12- A chupeta ortodôntica, ao contrário da convencional, pode ser utilizada indiscriminadamente, pois não traz alterações nos dentes, músculos, fala e respiração.

( ) $\operatorname{SIM}($ ) NÃO 
13- Sobre a mamadeira, assinale a afirmativa correta:

( ) As possíveis alterações nos dentes e músculos causadas pelo hábito de sucção serão resolvidas automaticamente quando o hábito for removido, independentemente da idade da criança.

( ) A mamadeira deve ser substituída gradativamente pelas canecas com canudos a partir dos 5 anos de idade.

( ) Quando o furo do bico é aumentado provoca enchimento rápido do estômago e não trabalha os músculos da face do bebê.

( ) O bebê que foi amamentado por leite materno, até os 2 anos de idade deverá continuar a amamentação com mamadeira até os 4 anos de idade.

14- Sobre o Teste da Linguinha, assinale a afirmativa correta:

( ) A Língua presa ocorre quando uma pequena porção de tecido, desaparece durante o desenvolvimento do bebê na gravidez.

( ) O teste da linguinha é um exame padronizado que possibilita diagnosticar e indicar o tratamento precoce das limitações dos movimentos da língua.

( ) O teste da linguinha pode ser realizado por qualquer individuo que receba orientação, até mesmo pela mãe do bebê.

( ) A língua presa não está relacionada com possíveis dificuldades para mamar encontradas por alguns bebês.

Por favor, escreva aqui seu comentário ou sugestão, se houver.

( ) Não precisa escovar os dentes de leite, pois eles caem e nascem outros no lugar. 